\title{
Prevalence of Ascariasis in Selected Communities of Adamawa Northern Senatorial District
}

\author{
Ahmad Musa Kochifa ${ }^{1}$, Mahmoud Tanko Mohammed ${ }^{1, ~ *, ~ Y a k u b u ~ M o h a m m e d ~ S a n i ~}{ }^{2}$ \\ ${ }^{1}$ Department of Biomedical and Pharmaceutical Technology, Federal Polytechnic, Mubi, Nigeria \\ ${ }^{2}$ Department of Biological Sciences Technology, Federal Polytechnic, Mubi, Nigeria
}

Email address:

mahmoudtanko50@fpmubieportal.edu.ng (M. T. Mohammed)

${ }^{*}$ Corresponding author

\section{To cite this article:}

Ahmad Musa Kochifa, Mahmoud Tanko Mohammed, Yakubu Mohammed Sani. Prevalence of Ascariasis in Selected Communities of Adamawa Northern Senatorial District. Biomedical Sciences. Vol. 7, No. 2, 2021, pp. 60-63. doi: 10.11648/j.bs.20210702.14

Received: May 2, 2021; Accepted: May 18, 2021; Published: May 27, 2021

\begin{abstract}
Ascariasis is a disease caused by the parasite known as Ascaris lumbricoides. The adult worms are known to affect the nutritional status of patients, mostly children under the age of five (5), leading to malnutrition and night blindness due to Vitamin A deficiency. The long term effect of the malnutrition is retarded growth; other symptoms are intermittent colicky cramps, loss of appetite, and obstruction of the intestinal tract. In this paper, the prevalence of Acariasis in 15 communities across 3 local governments in Adamawa North Senatorial District, Adamawa State, Nigeria was reported. A total of 450 faecal samples were collected from the participants after obtaining permission from relevant authorities including parents and guardians of underaged participants. The samples were then subjected to standard parasitological procedures such as direct mount and sedimentation method for detection of adult worms and eggs. The results obtained shows that Mubi-North (13.3\%) recorded the highest prevalence compared to Mubi-South (11.1\%) and Maiha (9.1). In relation to gender, the prevalence in males $(37.3 \%)$ is slightly higher than that of females $(28.9 \%)$. Lastly, the age-related prevalence shows that children of lower age groups are more infected than adults of higher age groups. Ascariasis is very common in communities with inadequate sanitation facilities, andit can be controlled through sensitization about improving personal hygiene and provision of portable water and sanitation facilities.
\end{abstract}

Keywords: Ascariasis, Prevalence, Communities, Sanitation

\section{Introduction ${ }^{1}$}

Ascariasis is a disease caused by the parasite known as Ascaris lumbricoides. The adult form of this parasite reside in the small intestine, particularly jejunum of man, the female worm lays enormous number of eggs (nearly 200,000 per day) which are passed through the faeces. Furthermore, the eggs have to undergo incubation in the soil before developing rhabditiform larvae that are pathogenic to man. The disease has a worldwide distribution, with majority of the cases found in the tropics, such as Nigeria, India and china [1]. Global estimates for people infected with Ascaris lumbricoides is 819.0 million as of 2010 [2]. The World Health Organisation [3], reported

\footnotetext{
${ }^{1}$ We wish to acknowledge TETFUND-NIGERIA for providing the grant to conduct this research under the Institutional Based Research Grant (IBR).
}

that $10 \%$ of the population of the developing world is mostly infected by Ascaris, causing about 60,000 deaths annually, mainly in children. According to [4], Nigeria has a prevalence of $25.4 \%$.

The adult worms are known to affect the nutritional status of patients, mostly children under the age of five (5), leading to malnutrition and night blindness due to Vitamin A deficiency. The long term effect of the malnutrition is retarded growth; other symptoms are intermittent colicky cramps, loss of appetite, and obstruction of the intestinal tract. Their presence in the trachea may lead to respiratory obstruction [1]. Furthermore, Ascariasis is responsible for $22 \%$ of the 4.98 million YLDs attributable to soil transmitted helminths. 2,824 deaths attributable to A. lumbricoides in 2010, brings the DALYs contributed by the parasites infection to 1.31 million, [5]. The two major ways of controlling Ascariasis are by sanitation and chemotherapy. Although, control by sanitary 
measures is a slow process requiring a base of health education and social and economic development. That is where chemotherapeutic control can be used as the main weapon against the disease if sanitation cannot be improved in the short term, [6]. Ascariasis can be treated with Pyrantelpamoate, Mebendazole and Piperazine citrate. These drugs are generally inexpensive. Prophylaxis is by proper disposal of human faces, avoidance of eating raw vegetables \& salads, periodic treatment of ascariasis.

A greater estimate is most likely obtainable in Nigeria, considering its rapid population growth when compared to inadequate provision of Water Sanitation and Hygiene (WASH) facilities. Adamawa state Northern senatorial district is even at a higher risk of increase in prevalence, due to destruction of food, shelter, toilets, health facilities and sources of safe drinking water as a result of over a decade long ongoinghumanitarian crisis due to "Boko Haram" insurgency. The population of most of the communities under this district has doubled due to influx of internally displaced persons from neighboring towns and villages of Borno state affected by the Occupation, leading to overcrowdings, thus; enhancing the modes of transmission of Ascariasis. As such, it has become necessary to conduct a prevalence based study in these affected communities, to ascertain the level of infection, in order to generate a baseline data to assist government and other development partners in planning control programs.

\section{Materials \& Methods}

\subsection{Study Design and Population}

Adamawa North-Senatorial District lies between latitude $9^{\circ} 30^{\prime}$ and $11^{\circ}$ north of the equator and longitude $13^{\circ}$ and $13^{\circ}$ $45^{\prime}$ 'east of the Greenwich meridian. The region is bordered by Borno state in the west, by Hong and Song local government areas and in the south and east by the Republic of Cameroon. It has a land area of $4728.77 \mathrm{~km}^{2}$ and a population of 759,045 in 2003 (1991 Census Projected Figure) [7].

The vegetation falls within the Sudan Savanna belt of Nigeria's vegetation zone. The vegetation type is best referred to as combretaceous woodland savanna [8]. The temperature in Mubi region is warm which is relatively distributed throughout the year. The mean annual rainfall ranged from $900 \mathrm{~mm}-1050 \mathrm{~mm}$ [7].

\subsection{Sample Collection}

This research was carried out in 15 communities, across 3 local governments of Adamawa North Senatorial District, prior to the start of the study; permission was sought from relevant authorities. Equal numbers of study participants were selected from 3 categories (adults, children, and male/female) by simple random sampling in all locations.

The samples from Adult participants were collected after seeking their consent and informing them about what it would be used for, while in the case of underage participants the consent of their parents/guardians were sort. Clean sterile screwed capped bottles were then issued to all participants. The bottles were labeled clearly with name, sex, age and location. Instructions were then given to all participants on how to collect the samples into the sample bottles.

\subsection{Preparation of Samples}

A total of 450 Stool samples were collected into a sterile container and transported to the microbiology laboratory, Department of Biomedical and Pharmaceutical Technology, Federal Polytechnic Mubi, for processing. Samples were examined macroscopically for the consistency, presence of worms and eggs. Direct wet mount following stool concentration using the formalin ether method was prepared according to Cheesbrough [9].

\subsubsection{Direct Microscopic Examination}

A small amount of sample was mixed with saline solution $(0.9 \%)$ in a petri dish and stirred with a sterile glass road to ensure it was thoroughly mixed. A few drops of the homogeneous mixture were taken and placed on a clean sterile glass slide, and then covered with a clean cover slip. Asacris eggs were observed under microscope at $\times 10$ and $\times 40$ magnification.

\subsubsection{Sedimentation}

$1 \mathrm{~g}$ of feaces was suspended $5 \mathrm{ml}$ of $5 \%$ acetic acid solution by shaking. The suspension was then kept for one minute to settle and then filtered through a tiny mesh into a centrifuge tube. An equal amount of ether was then added, mixed and further shaken vigorously before it was centrifuged for one minute at 1,500rpm. After the sediment was formed, the supernatant was discarded and the sediment was mixed with equal amount of distilled water, mixed homogeneously and a few drops of the mixture were placed on a clean glass slide and examined under microscope at $\times 10$ and $\times 40$ magnification.

\subsection{Data Analysis}

Data obtained from the study was analyzed using Microsoft office excel and IBM SPSS v21. Statistical significance was set at $\mathrm{P}<0.5$ for $95 \%$ confidence limit.

\subsection{Ethical Approval}

Permission was sought from relevant authorities, parents/guidance of children as well as those old enough to consent to the study participation. The study will comply with the principles of Helsinki.

\section{Results}

Table 1 summarises the prevalence of ascariasis across 3 selected local government areas of Adamawa North Senatorial District. Out of the 450 samples examined, 151 $(33.56 \%)$ were positive for human ascariasis. The highest prevalence per local government was recorded in Mubi North 
(13.3\%), followed by Mubi South (11.1\%), while Maiha was the least with $(9.1 \%)$. The results of this current study also show that sex-related prevalence was significantly $(\mathrm{P}<0.005)$ higher among females (37.3\%) than their male (29.8\%) counterparts as presented in Table 2. Results obtained from age-related prevalence (Table 3 ) revealed that the age group of 10-19 had the highest prevalence (8.2\%) than all other age groups examined in this study.
Table 1. Distribution and prevalence of Ascariasis in Adamawa North Senatorial District.

\begin{tabular}{llll}
\hline Local Government & No. Examined & No. Infected & \% Infected \\
\hline Mubi North & 150 & 60 & 13.3 \\
Mubi South & 150 & 50 & 11.1 \\
Maiha & 150 & 41 & 9.1 \\
Total & 450 & 151 & 35.5 \\
\hline
\end{tabular}

$\mathrm{X}_{\text {cal }}^{2}=31.13, \mathrm{Tab}=23.17, \mathrm{p}<0.05$.

Table 2. Sex-related prevalence of Ascariasis in Adamawa North Senatorial Districts.

\begin{tabular}{|c|c|c|c|c|c|c|}
\hline & Males & & & Females & & \\
\hline LocalGovt. & No. Examined & No. Infected & $\%$ Infected & No. Examined & No. Infected & $\%$ Infected \\
\hline Mubi-N & 75 & 33 & 14.7 & 75 & 27 & 12.0 \\
\hline Mubi-S & 75 & 28 & 12.4 & 75 & 22 & 9.8 \\
\hline Maiha & 75 & 23 & 10.2 & 75 & 18 & 8.0 \\
\hline Total & 225 & 84 & 37.3 & 225 & 67 & 29.8 \\
\hline
\end{tabular}

$\mathrm{X}_{\mathrm{cal}}^{2}=10.59, \mathrm{Tab}=19.73, \mathrm{p}<0.05$.

Table 3. Age-related prevalence of Ascariasis in Adamawa north senatorial Districts.

\begin{tabular}{llll}
\hline Age & No. Examine & No. Infected & \% Infected \\
\hline $10-19$ & 75 & 37 & 8.2 \\
$20-29$ & 75 & 31 & 6.9 \\
$30-39$ & 75 & 29 & 6.4 \\
$40-49$ & 75 & 24 & 5.3 \\
$50-59$ & 75 & 18 & 4.0 \\
$60-70$ & 75 & 12 & 2.7 \\
Total & 450 & 151 & 33.5 \\
\hline
\end{tabular}

$\mathrm{X}_{\mathrm{cal}}^{2}=13.71, \mathrm{Tab}=21.32, \mathrm{p}<0.05$.

\section{Discussion}

The findings of this research reveal that human ascariasis is highly prevalent in Adamawa North Senatorial District, which is similar with the findings of a study conducted in Konduga Local Governmet, Borno State by Dagem et al., [10, 11]. There is a high tendency that a greater number of persons might be infected when the finding is translated to the general population. The pattern of infection may be as a result of overcrowdings due to influx of internally displaced persons from neighboring Borno towns that fled their homes as a result of the "Boko Haram" insurgency. Furthermore, inadequate Water, Sanitation, and Hygiene facilities, poor personal hygiene practices may also have great impact in the spread of the disease.

With regards to gender, it was discovered that the males had a higher prevalence than their female counterparts, which agrees with findings of $[12,13]$. This can be attributed to exposed lifestyle of males, such as eating outside and having contact with numerous individuals at places of work or business premises.

The age related prevalence was found to be higher in children of the age group of 10-19 years old, which may be attributed to their exposure to contaminated soils in play grounds, and eventually using unwashed hands to eat food and fruits $[14,15]$.

\section{Conclusion}

The high prevalence of Ascariasis in this study indicates that the disease is a public health problem in Adamawa Northern Senatorial District. The figures can be even more alarming when translated to the general population. Lack of awareness about Ascariasis and its mode of transmission are leading causes of the disease spread. Improper disposal of human feaces and open defecation, which are common practices in these endemic areas are known to enhance transmission of the parasite. It is therefore recommended that Government and NonGovernmental Authorities should partner with Heads of Local Traditional and Religious groups in intervention and control programmes such as; De-worming, provision of water and sanitation facilities, sensitization campaigns that will promote personal hygiene.

\section{References}

[1] Arora D. R., Arora B. B (2004). Medical Parasitology, 2nd ed. CBS Pulishers \&Distributors, Darya Ganj, New Delhi. P192195.

[2] Nigerian Center for Disease Control (NCDC), 2017. Soil transmitted Helminths. www.ncdc.gov.ng/diseases.

[3] World Health Organsation (2021). Water related Diseases. Retrieved

fromhttps://www.who.int/water_sanitation_health/diseases

risks/diseases/ascariasis/en/\#: :text=Ascariasis\%20is\%20a $\mathrm{n} \% 20$ infection $\% 20$ of,after\%20accidentally\%20swallowing $\% 20$ the\%20eggs. Accessed on $30^{\text {th }}$ April 30, 2021.

[4] Pullan R. L, Sturrock H. J. W, SoaresMagalhaes R J, Clements A. C. A, Brooker S. J (2012): Spatial parasites ecology and epidemiology: a review of methodsand applications. Parasitol. 2012, 139: 1870$1887.10 .1017 / \mathrm{s} 0031182012000698$ 
[5] Murray CJL, Salomon JA, Mathers CD, LOPez AD (2002): Summary measures of Population health: concepts, ethics, measurement and applications. Geneva: World Health Organisation.

[6] Pawlowski ZS, (1984); world health forum: Annales de la societebelge de medicine de tropical, 64 125-134.

[7] Adebayo A. A. (2010): Mubi region; ageographic Synthesis. $2^{\text {nd }}$ ed. Paraclete Publishers, Yola-Nigeria. Pp17-18.

[8] Areola O. O. (1983): Soil and Vegetation. A geography of Nigerian development. Heinemann, Ibadan.

[9] Cheesbrough M. (2005). District laboratory practice in Tropical Countries. 2nd ed. New York: Cambridge University Press International Committee of the Red Cross (2017). Nigeria Refugee crisis.

[10] Oluwole AS, Adeniran AA, Mogaji HO, Olabinke DB, Abe EM., et al. Prevalence, intensity and spatial co-distribution of schistosomiasis and soil transmittedhelminths infections in Ogun state, Nigeria. Parasitology Open. 2018; 4: e8, 1-9.
[11] Damen JG, Luka J, Biwan EI, Lugos M. Prevalence of Intestinal Parasites among Pupils in Rural North Eastern, Nigeria. Niger Med J. 2011; 52 (1): 4-6.

[12] Ekpo UF, Odoemene SN, Mafiana CF, Sam-Wobo SO (2008) Helminthiasis and hygiene conditions of schools in Ikenne, Ogun State, Nigeria. PLoSNegl Trop Dis 2: e146. doi: 10.1371/journal.pntd.0000146. pmid: 18357338.

[13] Mamman, A. S and Maikenti, J. Journal of Biology, Agriculture and Healthcare ISSN 2224-3208 (paper) ISSN 2225-093X (online) Volume 4, No. 23.

[14] Adikankwu, O. R., Odikamnoro, O., Uhuo, A. C. \& Nwuzo, A. C. The Prevalence of intestinal nematode in school children in Ebonyi State Local Government Area Ebonyi State, Nigeria. Cont. J. Biomed. Sci. 6, 13-17 (2012).

[15] Funso-Aina, O., Chineke, H., \& Adogu, P. (2020). A Review of Prevalence and Pattern of Intestinal Parasites in Nigeria (2006-2015). European Journal of Medical and Health Science, 2 (1). https://doi.org/10.24018/ejmed.2020.2.1.139. 